\title{
UM JOVEM MARXISTA NOS PRIMÓRDIOS DA SOCIOLOGIA DO TRABALHO: entrevista com Michel Löwy
}

\author{
ENTREVISTA
}

Ricardo Festi *

Publicamos a entrevista com Michel Löwy, realizada em sua casa, em Paris, no dia 06 de dezembro de 2016. As questões abordadas buscam explorar melhor (mas não apenas) as experiências do autor durante seu período de formação no curso de ciências sociais da Universidade de São Paulo, assim como a sua militância política, no final da década de 1950. Especificamente, Löwy nos traz um depoimento sobre sua passagem pela sociologia do trabalho, quando participou de uma pesquisa sobre consciência operária dos metalúrgicos do Brasil, sob a supervisão de Azis Simão, professor da USP, e a ajuda de José Albertino Rodrigues, então diretor do Departamento Intersindical de Estatística e Estudos Socioeconômicos (DIEE$\mathrm{SE}$ ). Um dos resultados desta pesquisa foi o artigo "Estrutura e consciência de classe operária no Brasil”, traduzido e publicado neste Dossiê.

Esperamos que esta entrevista, assim como o conjunto dos artigos publicados nesta revista, possa instigar os leitores a conhecer

* Universidade Estadual Paulista (Unicamp). Departamento de Humanas do COTIL.

Rua Paschoal Marmo, 1888. Jardim Nova Itália. Limeira São Paulo - Brasil. ricardofesti@gmail.com melhor a obra desse cativante e polissêmico teórico que é Michel Löwy. ${ }^{1}$

O senhor ingressou, em 1956, no Curso de Ciências Sociais da Universidade de São Paulo e teve como colegas Roberto Schwarz e os irmãos Sader, e como professores Fernando Henrique Cardoso, Octávio Ianni e Florestan Fernandes. Foi uma geração excepcional, que marcou as ciências sociais. Nesse marco, como foi o processo de sua formação e como o senhor hoje explicaria o fato de essa geração ter assumido um posto de destaque na produção intelectual brasileira?

Em primeiro lugar, nessa geração, tem de incluir Francisco Weffort, os irmãos Fausto, o Mauricio Tragtenberg, o Gabriel Cohn... É difícil defini-la, mas uma particularidade é que a maioria de nós se interessa pelo marxismo, buscava entendê-lo. Os professores nos ajudavam

1 Para aqueles que desejam conhecer outras entrevistas concedidas por Löwy, recomendamos Gomes e Reis (1996) e Jinkings e Sader (2004). Para uma reflexão sobre o conjunto de suas obras, ver Jinkings e Peschanski (2007) e Querido (2016). 
nisso, mas não era o suficiente. Então, buscávamos outras fontes, pois a dose de marxismo que recebíamos na USP era um pouco homeopática. Por isso, para alguns, não todos, ajudou muito a participação que tivemos no grupo de estudos de $O$ Capital de Marx. Isso foi no final dos anos 1950 e início dos anos 1960. Foi um lugar importante para nossa formação cultural, intelectual e política. Havia esse interesse pelo marxismo, mas também certa hostilidade ao tipo de marxismo feito pelo PCB e o "marxismo nacionalista" do ISEB, certo "marxismo carioca”, que também era identificado com o partidão, com ou sem razão, pois havia uma posição de que, em São Paulo, éramos mais sérios. Para alguns de minha geração, principalmente eu, os irmãos Sader, Paulo Singer e Ruy Mauro Marini, a POLOP ${ }^{2}$ cumpriu um papel importante no início dos anos 1960. Então, foi isso: uma geração diversa, não homogênea, em que muitos tiveram esse interesse pelo marxismo, alguns foram mais ativistas politicamente e outros mais ortodoxos em suas concepções.

Então, nesse momento, o marxismo entra, na sua formação e na de outros de sua geração, por fora da academia?

Minha formação marxista, na verdade,

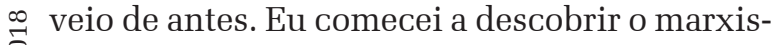
14 ou 15 anos de idade, pois comecei a militar muito cedo. Meu inspirador - sempre repito isso - foi Paulo Singer, que me ajudou a descobrir Rosa Luxemburgo, algo que foi N muito importante para mim. Portanto, quando Nิ eu cheguei à USP, eu já tinha uma formação œ. marxista. Inclusive, eu era um pouco dogmá-

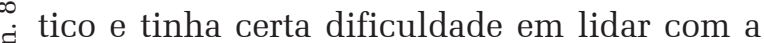
iे "sociologia burguesa”. Fui estudar ciências so-

2 A Organização Revolucionária Marxista - Política Operaria (POLOP) foi fundada em janeiro de 1961, como reస్ sultado da fusão de vários pequenos grupos de militantes, - simpatizantes de Rosa Luxemburgo e Trotsky, contrários à

Iinha política do PCB, que levava a uma capitulação frente

đu à burguesia. Após o Golpe de 1964, a POLOP deu origem

○ a várias outras pequenas organizações revolucionárias que seguiram o caminho da luta armada. Sobre o ISEB, ver To-

ledo (1977), e sobre as organizações de extrema esquerda das décadas de 1950 e 1960, ver Leal (2004) e Meyer (2009) ciais porque achava que era o mais próximo do socialismo. Tinha essa ideia ingênua de que, para quem se interessa pelo socialismo, o curso mais próximo seria o de Ciências Sociais. Mas foi nos tempos de USP que descobri um livro de Lucien Goldmann, que apresentava um marxismo aberto e arejado e que discutia com a sociologia acadêmica. Então, para mim, ele foi fundamental. Portanto, duas coisas marcaram minha formação marxista: em termos políticos, Rosa Luxemburgo; e, em termos de reflexão teórica, Lucien Goldmann.

Como foi seu ingresso no grupo de estudos de $O$ Capital? Ele era bastante restrito, não?

Bem restrito. No começo, era um grupo de professores. A maioria da geração mais nova. Os da geração mais antiga - o Florestan Fernandes, por exemplo - foram deixados de fora. Inclusive porque ele, na época, não se dizia marxista. De certa forma, o grupo de $\mathrm{O} C a$ pital foi formado contra o Florestan. Então, no começo, eram apenas os professores. Porém, em certo momento, foram convidados para participar alguns estudantes que o grupo considerava os mais avançados. Então, entramos, eu, Schwarz, Bento Prado... Acho que também o Ruy Fausto... Porém, pegamos o bonde andando... Acho que já estavam no final do volume 1. Há vários trabalhos sobre o grupo de $O$ Capital, como o do próprio Roberto Schwarz, que participou bem mais tempo e tem uma visão muito mais ampla que eu, pois logo vim para a França. ${ }^{3}$

O senhor realizou, em 1959, uma pesquisa sobre consciência de classe. Porém, antes de entrar nessa questão, gostaria de saber se essa demanda por estudar o marxismo e o mundo do trabalho tinha alguma relação com as transformações que a sociedade brasileira sofria. Digo isso, pois, em vários relatos de personagens de sua geração, destaca-se o processo de "modernização" e de industrialização ocorridos em ${ }^{3}$ Ver Schwarz (1998) e Rodrigues (2011). 
São Paulo. Até meados dos anos 1950, eram muito fortes, na USP, os temas relacionados aos processos de formação do Brasil, como a questão racial, por exemplo... Pode-se dizer que a questão do mundo industrial passou a fazer parte de várias pesquisas dessa geração?

Sem dúvida! Inclusive, esse foi o caso do Fernando Henrique Cardoso. Mas eu, pessoalmente, não me interessava muito por isso. O que me chamava a atenção era o outro lado, ou seja, as lutas operárias, que tinham certa relação com a industrialização. Foi devido a esse meu interesse que estabeleci uma relação muito próxima com Azis Simão, pois, na época, era quem mais se preocupava com as questões do movimento operário. Tínhamos muita afinidade. Por outro lado, eu havia criado uma relação com o Sindicato dos Metalúrgicos de São Paulo, que, na época, era dirigido pelo Partidão (PCB), em aliança com os trabalhistas e os socialistas. Eu tinha uma boa relação com eles, pois participava do Pacto de Unidade Intersindical, ${ }^{4}$ que congregava os metalúrgicos, a construção civil e outros sindicatos. Ele também era hegemonizado pelo Partidão. E eu era representante da União Estadual de Estudantes nessa frente. Além disso, eu tinha uma relação com o DIEESE e com o José Albertino Rodrigues. ${ }^{5}$ Aí trabalhei, ajudando no tratamento da pesquisa sobre a carestia, ou seja, o custo de vida das famílias operárias. Portanto, foi a partir dessa minha dupla relação com o Sindicato dos Metalúrgicos e com o DIEESE e da vontade de entender como se dava a politização dos militantes operários, que era o tema de Azis Simão, que desemboquei na pesquisa de 1959.

Poderia, então, nos falar mais sobre essa pes-

${ }^{4}$ O Pacto de Unidade Sindical foi criado em 1954 com o objetivo de dirigir as ações políticas e sindicais da classe operária no estado de São Paulo. Não foi reconhecido pelo Ministério do Trabalho.

${ }^{5}$ José Albertino Rodrigues foi responsável pela criação do Departamento Intersindical de Estatística e Estudos Socioeconômicos (DIEESE), em dezembro de 1955, que logo se tornou o principal órgão a assessorar com dados os sindicatos operários. quisa que realizou com os delegados do Congresso Nacional de Trabalhadores Metalúrgicos, na cidade de Itanhaém?

Essa pesquisa eu fiz com a Sarah Chucid, sob a orientação do Azis Simão. O grosso dela fui eu quem fez. A ideia era a de entender os vários níveis de consciência de classe. Foi então que fiz aquela tabela: identidade de classe, consciência sindical e consciência política. Com o acordo do DIEESE e do sindicato dos metalúrgicos, eu distribuí um questionário para os delegados do Congresso em Itanhaém. Nem todos, mas a maioria respondeu. E como eu era uma pessoa de confiança, eles viram logo que não se tratava de algo da polícia. E o questionário era anônimo. Tinha uma vocação para ser uma pesquisa empírica e, modestamente, tentar identificar as relações entre a consciência e fatores como a idade, o salário, os tipos de trabalho, os níveis de educação, dentre outras coordenadas. O objetivo, portanto, era ver as relações possíveis com o nível de consciência social e política. ${ }^{6}$

O resultado dessa pesquisa é exposto num artigo publicado em 1962, na Revista Brasileira de Estudos Políticos da UFMG, em coautoria com Sarah Chucid. Nesse texto, a principal referência metodológica foi a um psicólogo social chamado Richard Centers. Isso refletia a forte influência que as ciências sociais norte-americanas tinham na época?

Acho que não. Foi um pouco por acaso que eu descobri esse autor. Eu acredito que não houvesse muita relação. Pouco tempo depois, eu descobri Lukács e aí mudei o enfoque...

A descoberta de György Lukács ocorreu depois dessa pesquisa?

\footnotetext{
${ }^{6}$ Dois artigos foram publicados como resultado dessa pesquisa. O primeiro, em coautoria com Sarah Chucid, saiu na Revista Brasileira de Estudos Políticos em 1962, com o título "Opiniões e atitudes de líderes sindicais metalúrgicos". O segundo foi publicado em francês, em 1970, no Cahier Internationaux de Sociologie, e foi traduzido para este Dossiê.
} 
Eu não lembro se, no artigo de 1962, já aparece alguma referência a Lukács. Eu sei que aparece no que publiquei em 1970 na revista Cahiers Internationaux de Sociologie, na França. Eu lembro também que a pesquisa, na época, ganhou um prêmio que era dado ao melhor trabalho realizado pelos estudantes. Eu o compartilhei com a Sarah Chucid. Recebemos as obras completas de Lima Barreto. Depois, eu e o Roberto Schwarz fizemos uma brincadeira no grupo de $O$ Capital com esse meu artigo e o dele sobre esporte, sociologia do esporte. O Roberto, que tinha um alemão impecável, escreveu uma carta dirigida a mim, supostamente assinada por György Lukács, que afirmava haver recebido nossos artigos e os tinha achado formidáveis, etc. Levamos a carta para a reunião e eu disse: "Olhe, acabei de receber essa carta do Lukács". Demos para um amigo traduzir e ele leu a carta. Foi engraçado, pois alguns desconfiaram, outros nos deram parabéns e outros ficaram com inveja. Alguém chegou a dizer: "O Lukács exagera. Francamente, os artigos de vocês não são tão bons!”.

Antes de migrar para a França, o senhor teve uma passagem por São José do Rio Preto.

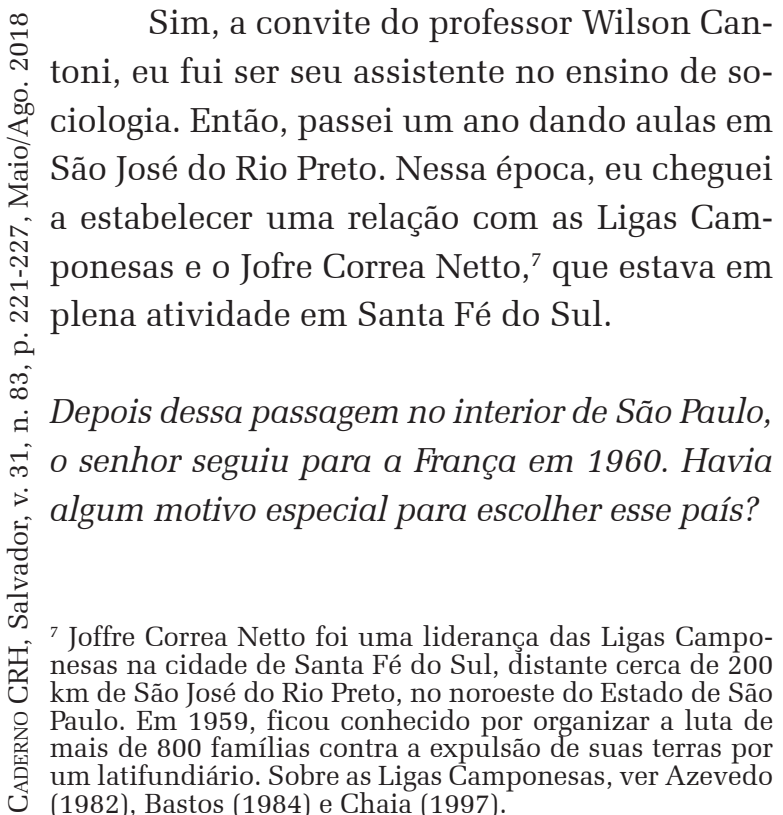

Sim, eu sempre tive muito interesse pela cultura francesa. Gostava de tudo que era francês: música, história, jornalismo, política, o surrealismo... Estudei francês na Aliança Francesa, então eu tinha uma relação forte com a cultura francesa. E sempre tive um pouco a ideia de estudar na França, sobretudo depois que descobri o Lucien Goldmann. Tinha esse projeto de estudar com ele.

\section{E o senhor recebeu uma bolsa?}

Sim, uma bolsa do governo francês.

Quando chegou a Paris, a sociologia era fortemente influenciada por uma perspectiva empiricista, algo que Goldmann critica em sua obra...

Sim, ele critica. Mas, veja, não é bem assim. Por exemplo, eu seguia os cursos da Sorbonne e meus dois professores de sociologia, Raymond Aron e Georges Gurvitch, não tinham nada de empiricistas. Suas aulas eram pura teoria sociológica. Mas, efetivamente, num escalão mais baixo, predominava o empiricismo.

O senhor chegou a se encontrar com Alain Touraine ou Georges Friedmann em suas passagens pelo Brasil, no final dos anos 1950 e início dos 1960?

Com o Friedmann, seguramente, eu não tive contato. Mas é provável que tenha assistido a alguma conferência ou a alguma aula do Touraine. Na França, eu segui os cursos de Touraine e tinha uma boa relação com ele.

Nesse cenário do início dos anos 1960, como era a recepção do marxismo na academia francesa?

O marxismo era muito forte, estava em ascensão e tinha uma presença difusa. Ele tinha uma influência na cultura, na política, na academia... Sua força foi aumentando pouco a pouco e estourou em 1968. Havia vários fo- 
cos de interesse: havia aqueles que seguiam o Althusser, por exemplo. Eu seguia Goldmann, Lefebvre, Marcuse (que, nessa época, veio a Paris dar um curso). Além disso, tinha também o marxismo do Partido Comunista Francês, com seus historiadores e filósofos. E ele tinha certa incidência na academia. E tinha também o Sartre, que, nesse momento, se declarava marxista. Então, havia já um peso importante do marxismo. Porém foi no Brasil que eu tive a ideia de trabalhar sobre o jovem Marx.

E o senhor sentiu algum impacto, ou diferença positiva ou negativa entre sua formação na USP e a formação que seus colegas franceses tinham?

É difícil comparar. Em meu curso na Sorbonne, os dois principais professores eram Gurvitch e Aron. Aí já havia uma tensão. Mas, no Brasil também, pois, fora Fernando Henrique Cardoso e Octavio Ianni, havia poucos professores marxistas. O próprio Florestan, na época, não era. Então, é difícil comparar, pois são dois contextos bem diferentes.

Havia muitos estudantes latino-americanos na França nos anos 1960?

Latino-americanos havia bastante. Os mexicanos. Alguns peruanos... Mas não havia uma grande presença brasileira. Lembro que, na época, o único brasileiro que frequentava a universidade em Paris era o Rui Fausto.

Mas o senhor mantinha, ainda assim, um forte contato com o Brasil...

O meu contato era essencialmente com a POLOP, o Azis Simão e meus amigos, como o Schwarz. Mas o mais importante era com a POLOP, sobretudo com os irmãos Sader, que eram meus amigos mais próximos dessa organização. Eu mandava relatórios para eles sobre a situação na França e eles sobre o que se pas- sava no Brasil. Mas logo veio o golpe, e minha família emigrou para Israel, onde eu fui passar alguns anos. Não foi uma boa ideia, mas faz parte da vida.

Eu lhe pergunto sobre esses contatos, pois seu artigo publicado em 1970 termina com um panorama do pós-golpe e aponta algumas tendências políticas que não eram tão óbvias quando escreveu o texto, em 1969. Afirmou que, apesar do golpe militar e de várias lideranças terem sido presas, havia um processo de jovens que se radicalizavam em novas posições: cristãos de esquerda, castristas, maoístas, trotskistas... Então, eu imagino que essa informação não estava nos jornais e, por isso, me parecia que, de alguma maneira, o senhor mantinha um vínculo com essa militância que estava no Brasil.

Sim, eu mantinha esse vínculo e tinha fontes diretas sobre o que se passava no Brasil. Acompanhava tudo de perto. Eu me lembro de ter me encontrado com o Emir Sader, que passava por Paris, e conversamos muito. Quando eu voltei para a França, em 1970, a primeira coisa que a gente fez foi ir até o Sartre lhe pedir para redigir um protesto contra a tortura no Brasil. Eu não era exilado, como meus amigos, mas eu acompanhava muito o que se passava no Brasil. Em certo momento, em 1968, eu até pensei em retornar. Escrevi para o Azis Simão para saber se conseguiria trabalho e ele me desencorajou: "Não volte, pois aqui você já é bem conhecido e não passará do aeroporto!”.

Uma informação confirmada quando the foi retirado, pelo governo brasileiro, o direito ao passaporte, em 1975.

Sim.

O senhor retornou para a França em 1969 e foi trabalhar com o Poulantzas. Como foi essa relação? 
Quando cheguei em Paris eu fui logo ver o Goldmann. Eu queria continuar a trabalhar com ele, mas ele morreu em seguida, em outubro de 1970. O Emir Sader estava trabalhando como assistente do Poulantzas, mas resolveu ir para o Chile, devido à eleição do Allende. Então, Sader me apresentou ao Poulantzas: "Olha, meu amigo Michael, que também é marxista, poderia me substituir". Foi assim que eu fui recrutado para trabalhar na Paris-8.

Vocês chegaram a ter algum atrito ou debate mais caloroso, ainda que fraternal?

Não tínhamos acordo em muitas questões teóricas e políticas, mas nós nos dávamos muito bem. Ele era uma pessoa muito agradável. Ele era uma mistura de maoísmo com eurocomunismo. E eu era trotskista. Ele era althusseriano. Eu lukácsiano. Porém, acima disso, tínhamos como referência o marxismo, Marx, Lenin etc. Dávamos cursos juntos e, quando tínhamos desacordos, discutíamos na frente dos estudantes e eles adoravam. Então, nós nos dávamos muito bem. Ele, inclusive, foi membro de minha banca de doutorado de Estado, e aí foi engraçado, pois me disse: "Michael, você é um rapaz tão talentoso, porque perde o seu tempo com Lukács?”.

Eu gostaria de fazer uma última pergunta, dando um salto de mais de 40 anos. $O$ senhor tem retornado com bastante frequência ao Brasil nos últimos anos e eu sei que acompanha bastante a nossa situação política e os movimentos sociais. Queria saber a sua opinião sobre o que está se passando agora no Brasil.

Bom, eu exprimi a minha opinião em várias notas no blog da Boitempo. Primeiro, denunciando o golpe, eu cito aquela frase do Marx e do Hegel, a "História se repete, na primeira como tragédia e na segunda como farsa". Nós tivemos a tragédia com o golpe militar de 1964. E agora, tivemos o golpe-farsa, ou seja, os Cunhas e companhia, corruptos, levantan- do a bandeira da luta contra a corrupção e derrubando a Dilma, que foi acusada de todos os pecados, menos de corrupção, pois não conseguiram achar nada contra ela. Então, foi algo ridículo, grotesco. E isso ocorre numa situação em que a esquerda está em crise, pelos erros do PT, pelo fato de ele ter se comprometido com a corrupção e com as empreiteiras e tudo isso... E, de uma maneira mais geral, por ter decepcionado. Não posso prever o que vai acontecer, mas eu acho muito positivo o que aconteceu no Rio de Janeiro na campanha de Marcelo Freixo do PSOL. Acho isso um dos pontos de esperança no Brasil, atualmente. E tenho também muita esperança na dinâmica dos movimentos sociais, que são os que têm carregado a resistência a esse governo reacionário. Tem o MST, que eu acho que é um dos movimentos mais importantes do Brasil. O MTST e, mais recentemente, esse movimento dos secundaristas ocupando as escolas, que é realmente muito interessante. Há bons elementos de esperança, mas, nas eleições... As oligarquias ainda têm um poder muito grande. É uma situação contraditória.

Recebido para publicação em 15 de janeiro de 2018 Aceito em 24 de abril de 2018

\section{REFERÊNCIAS}

AZEVEDO, F. A. As ligas camponesas. Rio de Janeiro: Paz e terra, 1982.

BASTOS, E. R. As ligas camponesas. Petrópolis: Vozes, 1984.

CHAIA, V. Santa Fé do Sul: a luta dos arrendatários. Cadernos AEL, Campinas-SP, n. 7, 1997.

CHUCID, S.; LÖWY, M. "Opiniões e atitudes de líderes sindicais metalúrgicos". Revista brasileira de estudos políticos, Belo Horizonte, n. 13, jan.1962.

GOMES, A. de C.; REIS, D. A. Um intelectual marxista: entrevista com Michael Löwy. Tempo, Rio de Janeiro, v. 1, n. 2, p. 166-183, 1996.

JINKINGS, I.; SADER, E. "Michel Löwy". Margem esquerda: ensaios marxistas, n. 4, p. 9-20, out. 2004.

JINKINGS, I.; PESCHANSKI, J. A. (Org.). As utopias de Michael Löwy: reflexões sobre um marxista insubordinado. São Paulo: Boitempo editorial, 2007. 
LEAL, M. A esquerda da esquerda: trotskistas, comunistas e populistas no Brasil contemporâneo, 1952-1966. São Paulo: Paz e terra, 2004.

LÖWY, M. "Structure de la conscience de classe ouvrière au Brésil". Cahier internationaux de Sociologie, n. 49, p. 133-142, jul. 1970.

MEYER, V. Polop: uma trajetoria de luta pela organização. São Paulo: CVM, 2009.

QUERIDO, F. M. Michel Löwy: marxismo e crítica da modernidade. São Paulo: Boitempo, 2016.
RODRIGUES, L. S. A produção social do marxismo universitário em São Paulo: mestres, discípulos e 'um seminário' (1958-1978). 2011. 565 f. Tese (Doutorado em História Social) - Faculdade de Filosofia, Letras e Ciências Humanas, Universidade de São Paulo, São Paulo, 2011.

SCHWARZ, R. Um seminário de Marx. Novos estudos, n. 50, p. 99-114, mar. 1998.

TOLEDO, C. N. ISEB: fábrica de ideologias. São Paulo: Ática, 1977. (Ensaios, v. 28).

Ricardo Festi - Doutorando em sociologia pela Universidade Estadual de Campinas, com estágio de estudos na EHESS (Paris). Professor de sociologia no COTIL-UNICAMP. Publicações recentes: "A Instrumentalização da Subjetividade no Trabalho pelo Capital”, Educação e sociedade, v. 37, p. 913-916, 2016; e "Terrorismo jihadista e kamikazes humanos: uma difícil questão para a contemporaneidade", Mediações - Revista de Ciências Sociais, v. 21, p. 386, 2016. 
